Supporting information

\title{
Two-Dimensional Cytometry Platform for Single-Particle/Cell Analysis with Laser-Induced Fluorescence and ICP-MS
}

Chengxin Wu, Xing Wei, Xue Men, Xuan Zhang, Yong-Liang Yu, Zhang-Run Xu, Ming-Li Chen*, Jian-Hua Wang*

Research Center for Analytical Sciences, Department of Chemistry, College of Sciences, Northeastern University, Shenyang 110819, China

* Corresponding author

E-mail address: chenml@mail.neu.edu.cn (M.-L. Chen), jianhuajrz@ mail.neu.edu.cn (J.-H. Wang).

Tel.: +86 24 83688944. Fax: +86-24-83688944. 


\section{Table of Contents}

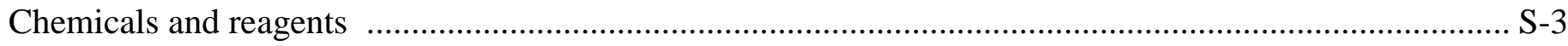

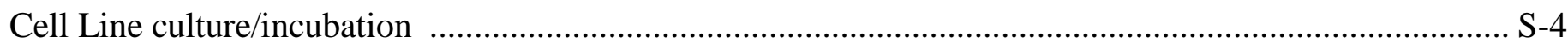

Numerical simulation

Figure S1 : Photograph of the two-dimensional cytometry platform (CytoLM) …................................ S-6

Figure S2: Simulated demonstration of Dean vortices in vortex capillary .......................................... S-7

Figure S3: Fluorescence images of the fluorescent particle trajectories ............................................. S-8

Figure S4: The response of LIF detector to chopper-induced laser strobing ….................................... S-9

Figure S5: The demonstration of peak identification by the data processing program ......................... S-10

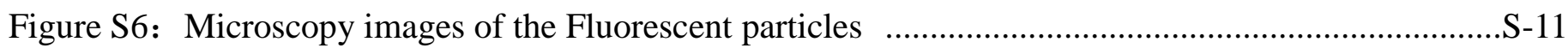

Figure S7: Frequency histogram and Gauss fit of the peak height/area from single-particle signals ...... S-12

Figure S8: Fluorescence imaging of the AO stained HepG2 cells in PBS …..................................... S-13

Figure S9: Frequency histogram of peak spacing from single-particle signals .................................. S-14

Figure S10: Frequency histogram and Gauss fit of the peak height/area from single-cell signals .......... S-15

Figure S11: MTT assay results of $\mathrm{Ag}^{+}$incubated HepG2 cells ........................................................ S-16

Figure S12: Frequency histogram and Gauss fit of the peak height of single-cell signals from CytoLM S-17

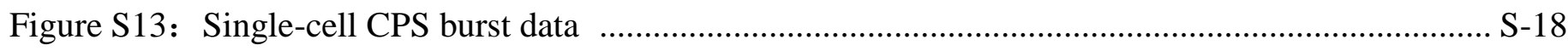

Table S1: ICP-MS instrumental and operational parameters .......................................................... S-19

Table S2: Results of single-fluorescent particle analysis by VCCS-LIF …....................................... S-20 


\section{Chemicals and reagents}

$\mathrm{AgNO}_{3}(\mathrm{AR}, \geq 99.8 \%$ ) was purchased from Sinopharm Chemical Reagent Co., Ltd (Shanghai, China). Fluorescent particles of $9.94 \pm 0.76 \mu \mathrm{m}$ size dimension with excitation/emission maxima of 525/565 nm were obtained from Bangs Laboratories (USA). The manufacturer-reported concentration is $1.832 \times 10^{7} / \mathrm{mL}$. Tween 20 is received from Aladdin Reagent Co., Ltd (Shanghai, China). Dulbecco's Modified Eagle Medium (DMEM) with high glucose is purchased from HyClone (USA), and fetal bovine serum (FBS) and penicillin-streptomycin solution are obtained from CLARK (Australia). Acridine orange (AO) was purchased from KeyGEN BioTECH Technology Co., Ltd. (Nanjing, China). All the other chemicals were used without further purification. The ultrapure water with a resistivity of $18.25 \mathrm{M} \Omega \cdot \mathrm{cm}$ (Milli-Q system, Millipore $\left.{ }^{\circledR}\right)$ was used throughout the experiments. All the reagents used are at least of analytical reagent grade.

Stock standard solutions of $\mathrm{Ag}^{+}(100 \mathrm{mg} / \mathrm{L})$ were prepared by dissolving the appropriate amount of $\mathrm{AgNO}_{3}$ in ultrapure water and diluted to desired concentration with phosphate-buffered saline (PBS) prior to use. The fluorescent particle suspension was prepared by diluting particle stock suspension to the desired concentration with ultrapure water containing $0.05 \%(\mathrm{v} / \mathrm{v})$ of Tween 20 . Before dilution, stock suspension of particles was sonicated for ca. 2 min. The particle suspension were stored at $4^{\circ} \mathrm{C}$, and sonication was performed before analysis. 


\section{Cell line culture/incubation}

\section{Cell line culture}

Living HepG2 cells are maintained in a DMEM medium containing 10\% (v/v) fetal bovine serum, 100 unit $/ \mathrm{mL}$ penicillin, and $100 \mathrm{mg} / \mathrm{mL}$ streptomycin. Cell culture is performed in a complete medium at $37^{\circ} \mathrm{C}$ under $5 \% \mathrm{CO}_{2}$ and the cells are passaged at a ratio of 1:2 every day to maintain their exponential growth phase.

\section{Fluorescent staining of HepG2 cells}

For AO staining, the HepG2 cells were washed with PBS and incubated in $200 \mu \mathrm{L}$ AO solution for 10 min at $4^{\circ} \mathrm{C}$ in the dark. Then, the AO stained HepG 2 cells were washed three times with PBS and re-suspended in PBS for microscopic observation or single-cell analysis. AO is a dye that can stain DNA and RNA within normal cells and give nucleus a bright green or yellow fluorescence.

\section{Cell viability assay}

Cell proliferation was determined by a colorimetric assay using MTT. Cell viability was conducted in complete medium per well in 96-well plate. HepG2 cultures were seeded at $5 \mathrm{k}$ cells per well $(100 \mu \mathrm{L})$. After 2 -h culture, $\mathrm{Ag}^{+}$standard solution $(0-30$ $\mathrm{mg} / \mathrm{L}, 10 \mu \mathrm{L}$ ) was added. The plate was then incubated in an atmosphere of $37^{\circ} \mathrm{C}, 5 \%$ $\mathrm{CO}_{2}$ for further $12 \mathrm{~h}$. Then $10 \mu \mathrm{L}$ MTT solution were added to each wall and incubation in cell incubator for $4 \mathrm{~h}$. Subsequently, the MTT solution is removed and the formazan crystals of each well are dissolved in $150 \mu \mathrm{L}$ DMSO allowing to vibration for $10 \mathrm{~min}$ and its absorbance at $570 \mathrm{~nm}$ was measured. The results were representative of at least three independent experiments. 


\section{Numerical simulation}

Computational fluid dynamics simulation was performed using Comsol Multiphysics

5.3. Based on the finite volume method, the extra fine mesh of the fluid path in the capillary is built by the physics-controlled method. The boundary layer conditions are not set. Different flow rates were specified at the input, and the outlet was set to a fixed-pressure boundary condition. No slip boundary condition was applied at the channel walls. The physical properties of water are applied to the fluids participating in the simulation (density $\rho=1000 \mathrm{~kg} / \mathrm{m}^{3}$ and dynamic viscosity $\mu=0.001 \mathrm{~Pa} \cdot \mathrm{s}$ ). The Viscous (Laminar) model is used to explore fluid phenomena in the microchannels. 


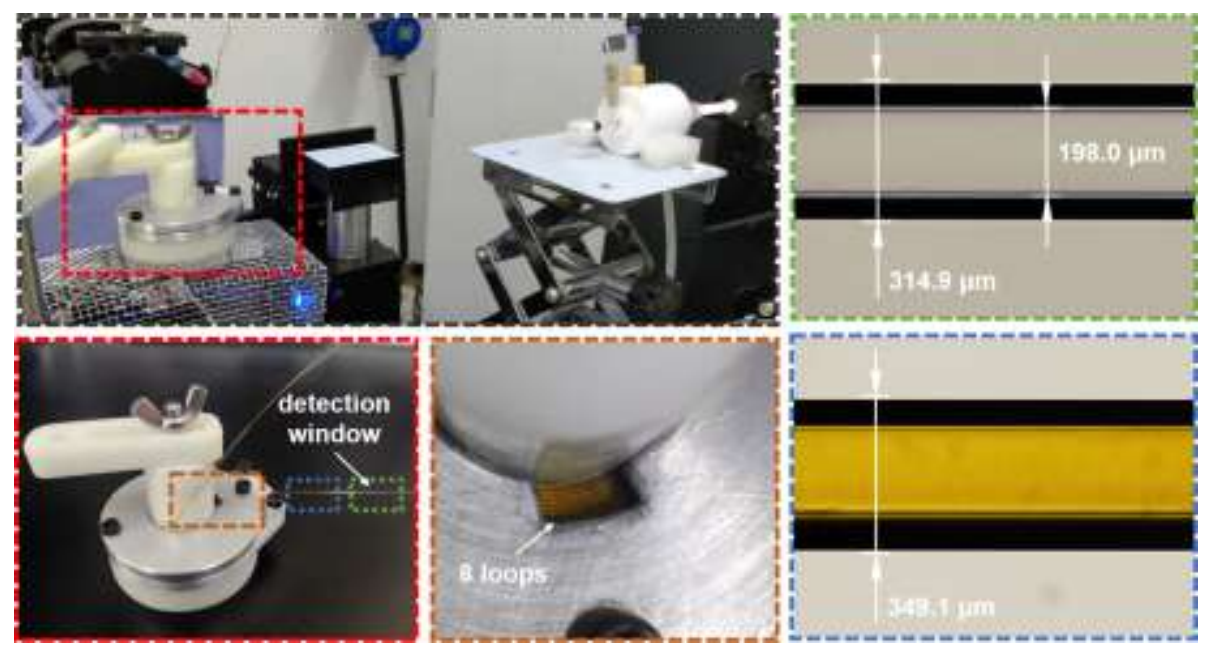

Figure S1. Photograph of the two-dimensional cytometry platform (CytoLM). 


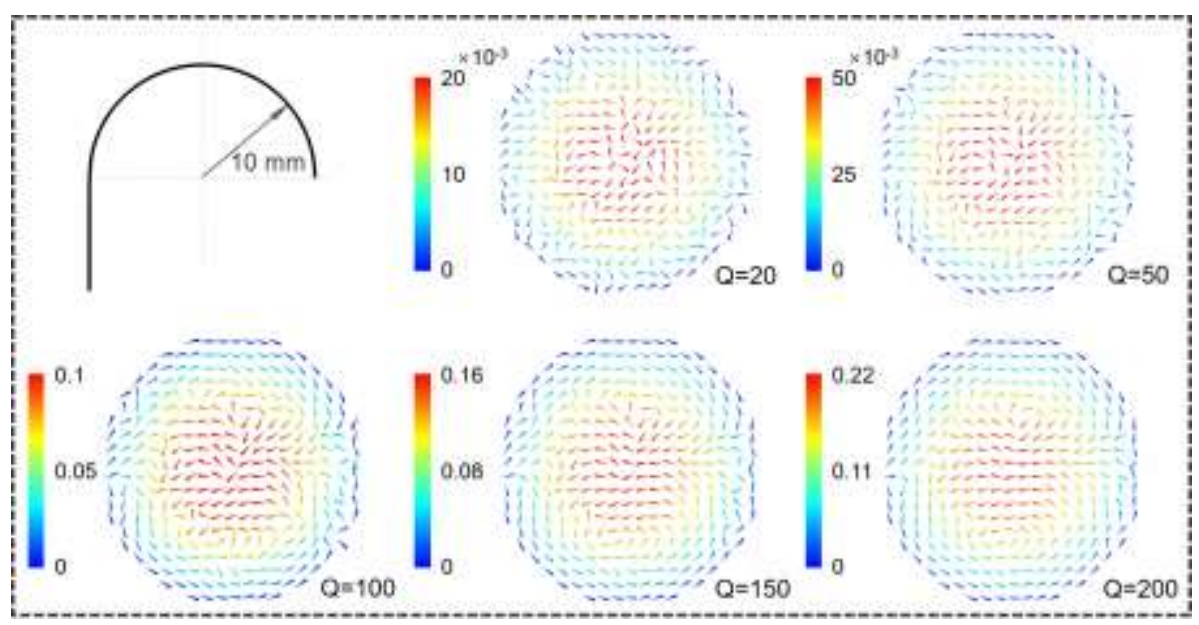

Figure S2. Simulated demonstration of Dean vortices in the vortex capillary at various fluid velocities $(\mathrm{Q}, \mu \mathrm{L} / \mathrm{min})$. The main experimental parameters: initial radius, $10 \mathrm{~mm}$; tubing spacing, $0.36 \mathrm{~mm}$; number of windings, 8 loops. 

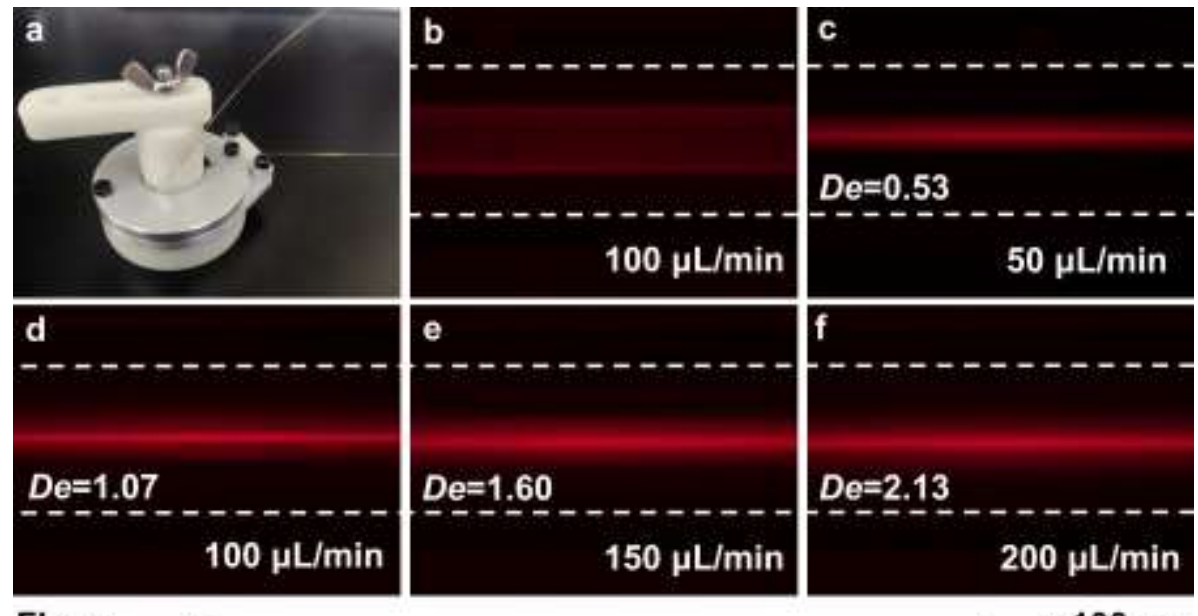

Flow

$100 \mu \mathrm{m}$

Figure S3. Fluorescence images of the fluorescent particle trajectories. (a) The photograph of vortex capillary cell sampling (VCCS) unit; (b) Fluorescence image of the fluorescent particle trajectories in the outlet region of straight capillary channel (effective length $15 \mathrm{~cm}$ ); (c-f) Fluorescence images of the fluorescent particle trajectories in the outlet region of the VCCS at various fluid velocities. The main parameters of VCCS: initial radius, $10 \mathrm{~mm}$; tubing spacing, $0.36 \mathrm{~mm}$; number of windings, 8 loops. 


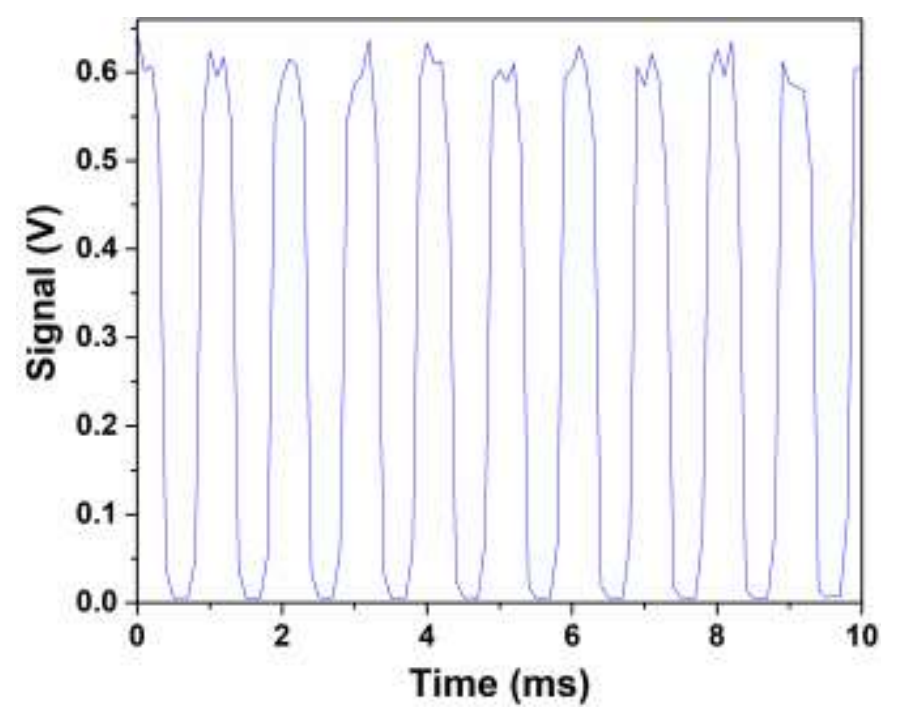

Figure S4. The response of the LIF detector to chopper-induced laser strobing.

Chopper frequency: $1 \mathrm{kHz}$. Sampling frequency: $40 \mathrm{kS} / \mathrm{s}$ with a 4-point smooth. 


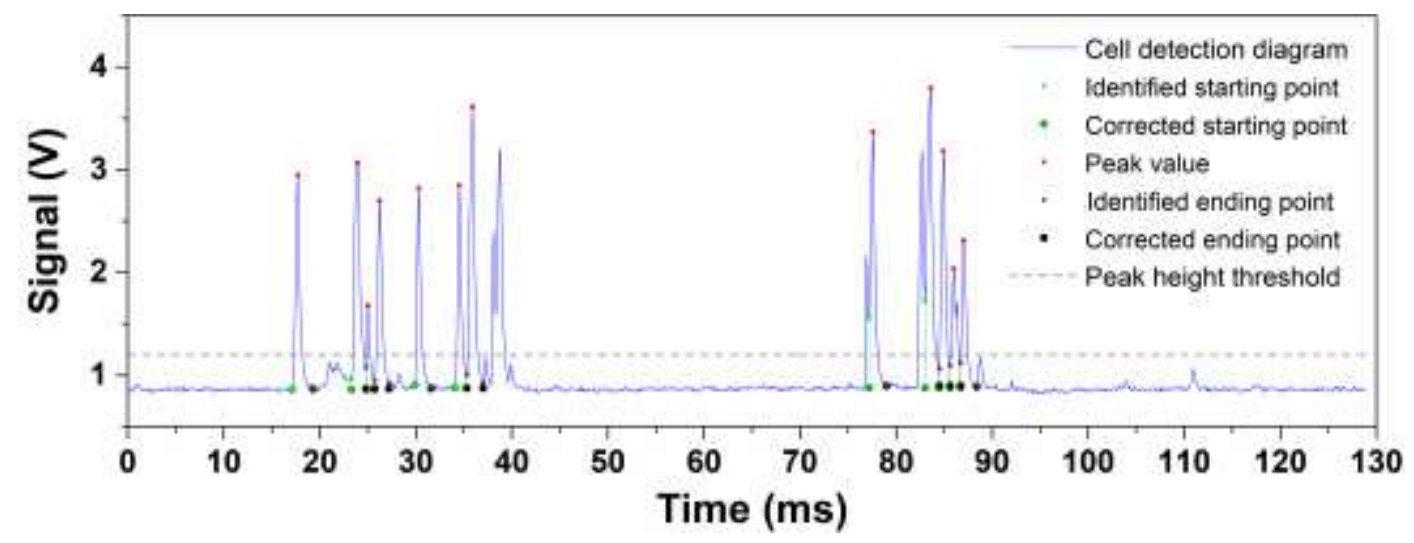

Figure S5. The demonstration of peak identification by the data processing program. The starting point is identified with threshold $\delta_{s}=\mathrm{n}_{\mathrm{s}} \cdot \sigma_{F O} \cdot \sigma_{F O}$ is the standard deviation of the first derivative of the baseline. The end point is identified with threshold $\delta_{e}=$ $\mathrm{n}_{\mathrm{e}} \cdot \sigma_{F 0}$. By adjusting the value of $\mathrm{n}_{\mathrm{s}}$ and $\mathrm{n}_{\mathrm{e}}$, the ideal peak recognition effect can be achieved. Overlapping peaks are identified and subtracted when their starting or ending point is higher than 0.3 times of the peak value. The peak height threshold is defined as $\delta_{m}=\mathrm{n}_{\mathrm{m}} \cdot \sigma_{H O}\left(\sigma_{H O}\right.$ is the standard deviation of the baseline). 

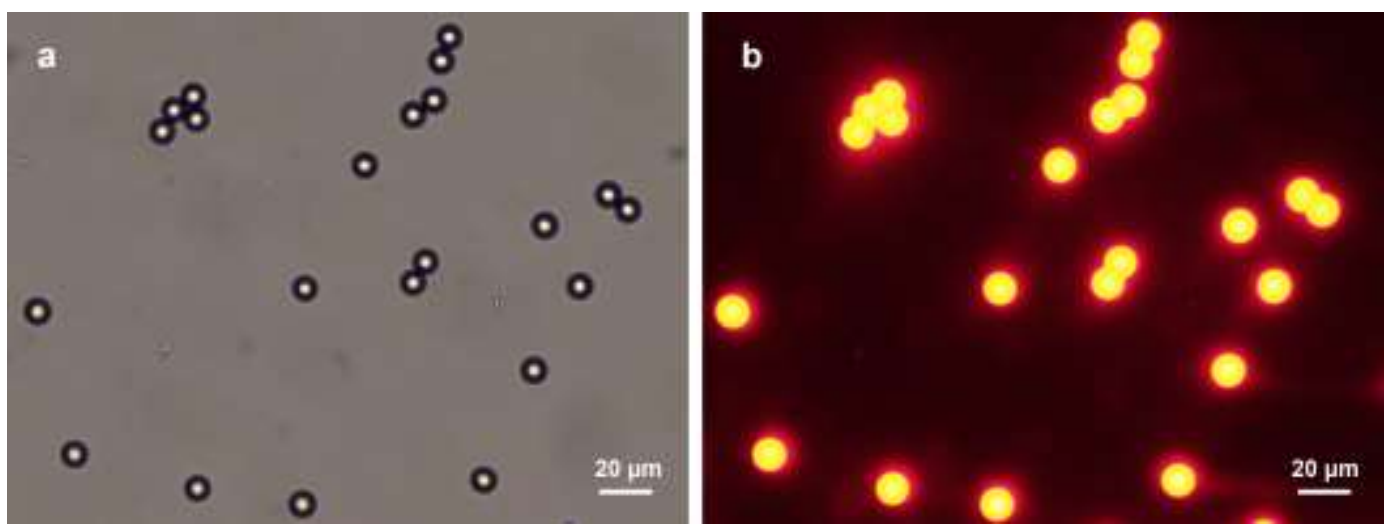

Figure S6. Bright-field microscopy image (a) and dark-field fluorescence image (b) of the fluorescent particles; $\lambda_{\text {ex }}$ in fluorescence image was $532 \mathrm{~nm}$, the exposure time was $2 \mathrm{~s}$. 

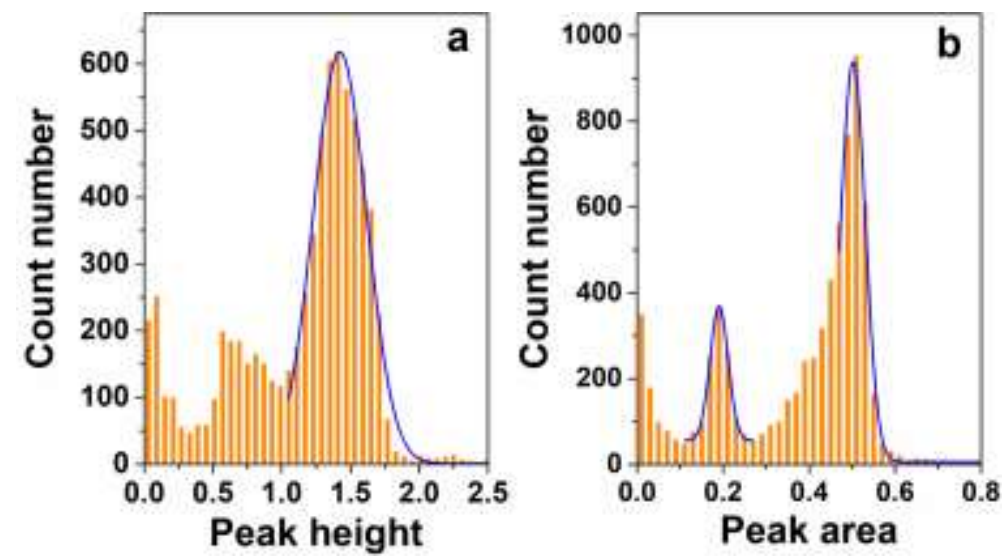

Figure S7. Frequency histogram and Gauss fit of the peak height (a) and peak area (b) from single-particle signals (60 s). Experimental parameters: particle density, $9.16 \times$ $10^{4} / \mathrm{mL}$; velocity, $100 \mu \mathrm{L} / \mathrm{min}$. 

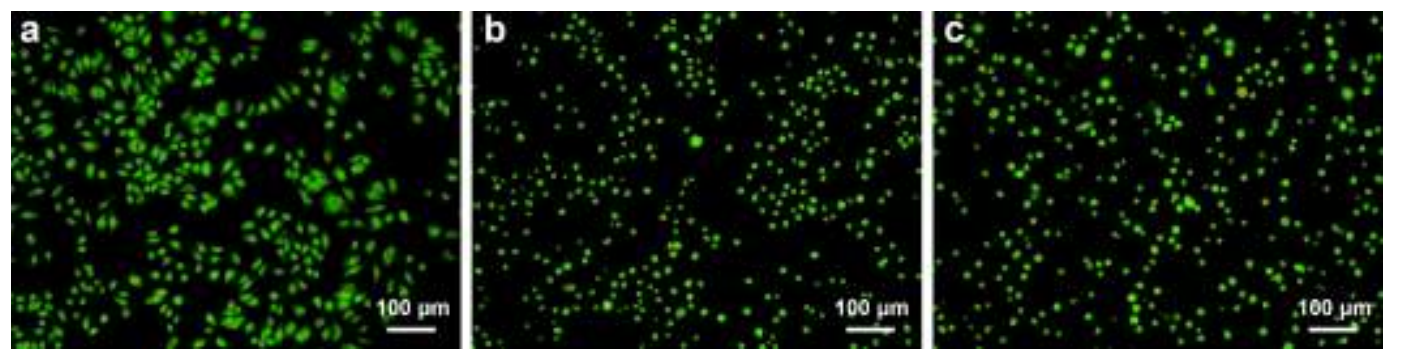

Figure S8. Fluorescence imaging of the AO stained HepG2 cells in PBS. (a) Adherent HepG2 cells; (b) Suspended HepG2 cells; (c) Collected HepG2 cells after VCCS-LIF analysis. 

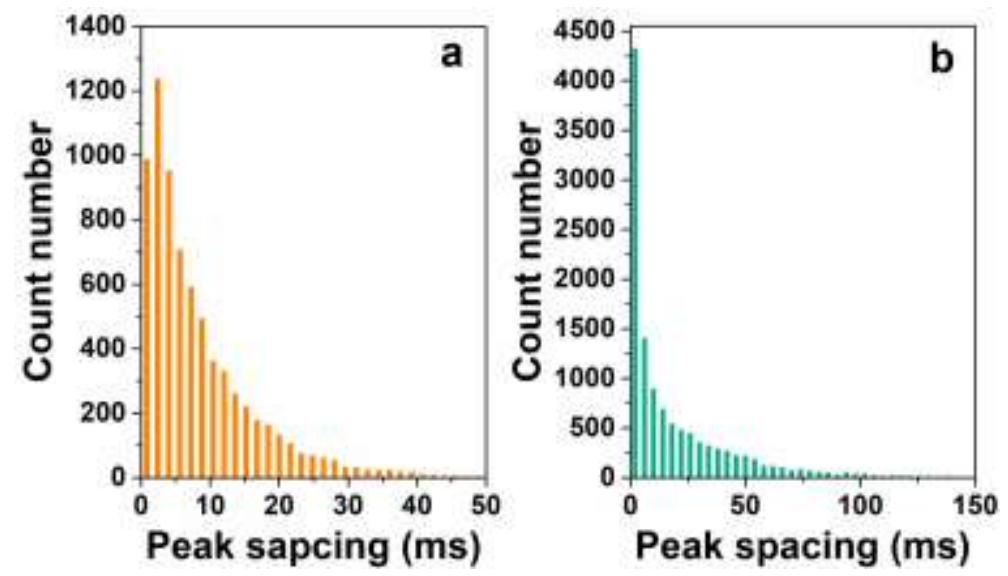

Figure S9. Frequency histogram of peak spacing from single-particle signals in $60 \mathrm{~s}$ (a) and single-cell signals in $240 \mathrm{~s}$ (b). Experimental parameters: particle density, 9.16 $\times 10^{4} / \mathrm{mL}$; cell density $1.5 \times 10^{5} / \mathrm{mL}$; velocity, $100 \mu \mathrm{L} / \mathrm{min}$ for particles and $50 \mu \mathrm{L} / \mathrm{min}$ for cells. 

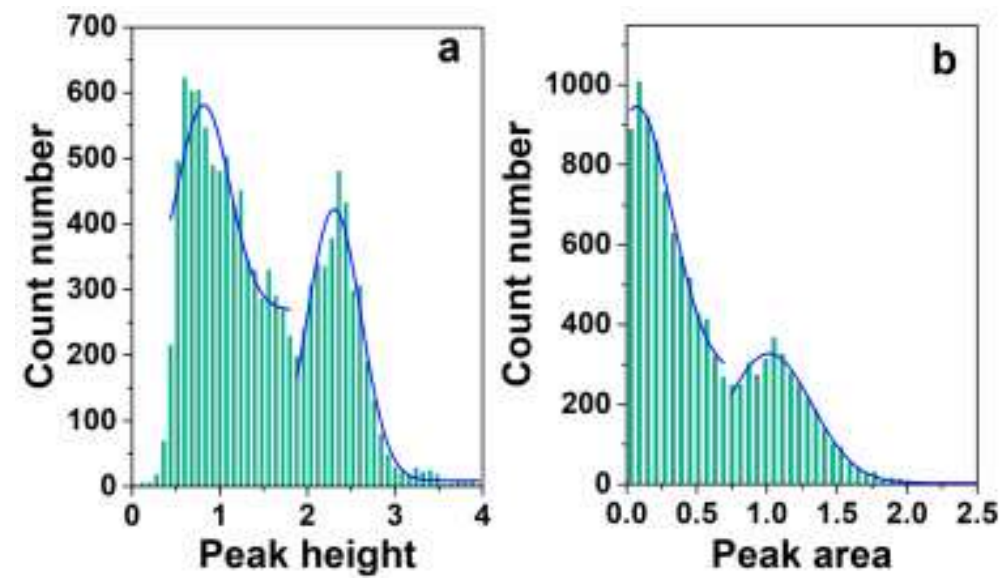

Figure S10. Frequency histogram and Gauss fit of the peak height (a) and peak area (b) from single-cell signals (240 s). Experimental parameters: AO stained HepG2 cells with a density of $1.5 \times 10^{5} / \mathrm{mL}$; velocity, $50 \mu \mathrm{L} / \mathrm{min}$. 


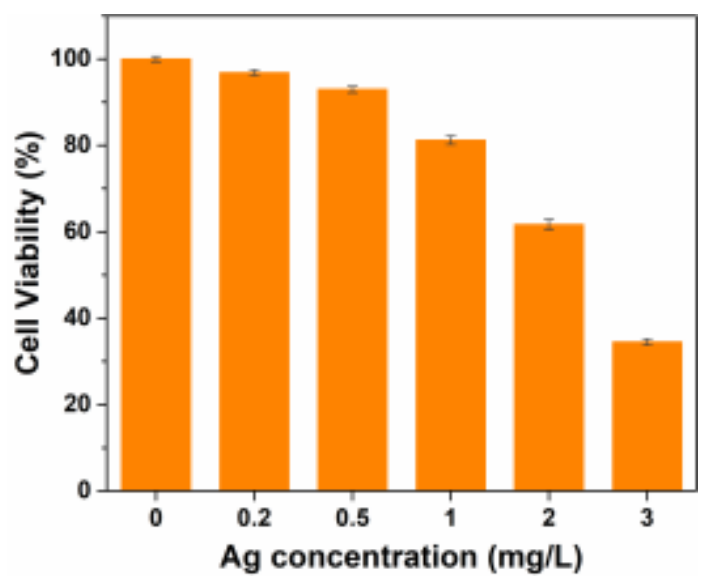

Figure S11. MTT assay results of the $\mathrm{Ag}^{+}$incubated HepG2 cells for $12 \mathrm{~h}$. The concentrations of $\mathrm{Ag}^{+}$are $0,0.2,0.5,1,2$, and $3 \mathrm{mg} / \mathrm{L}$. 

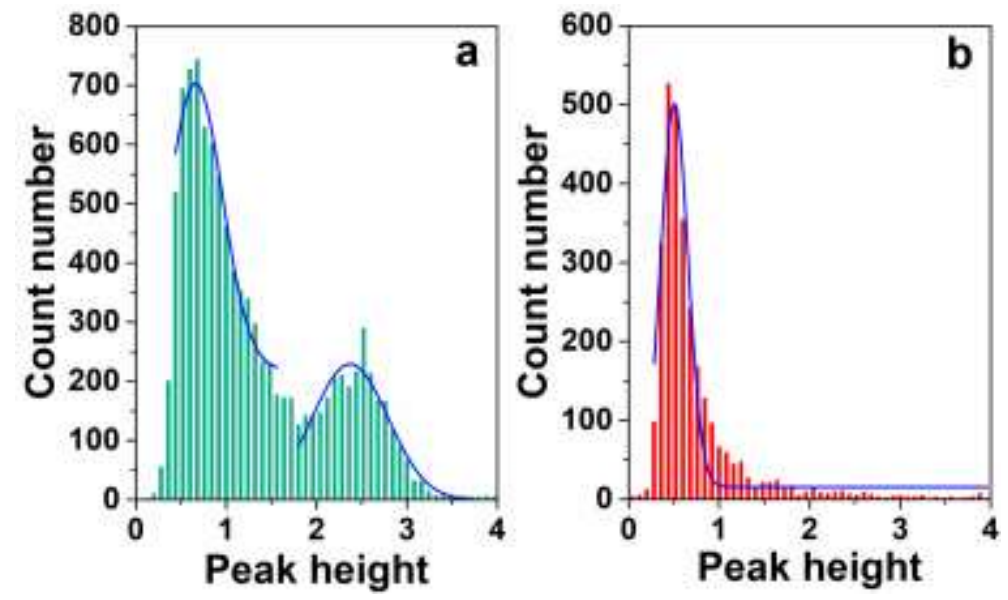

Figure S12. Frequency histogram and Gauss fit of the peak height of single-cell signals (240 s) obtained from LIF (a) and ICP-MS (b). Experimental parameters: AO stained HepG2 cells with a density of $1.5 \times 10^{5} / \mathrm{mL}$; velocity, $50 \mu \mathrm{L} / \mathrm{min}$. 

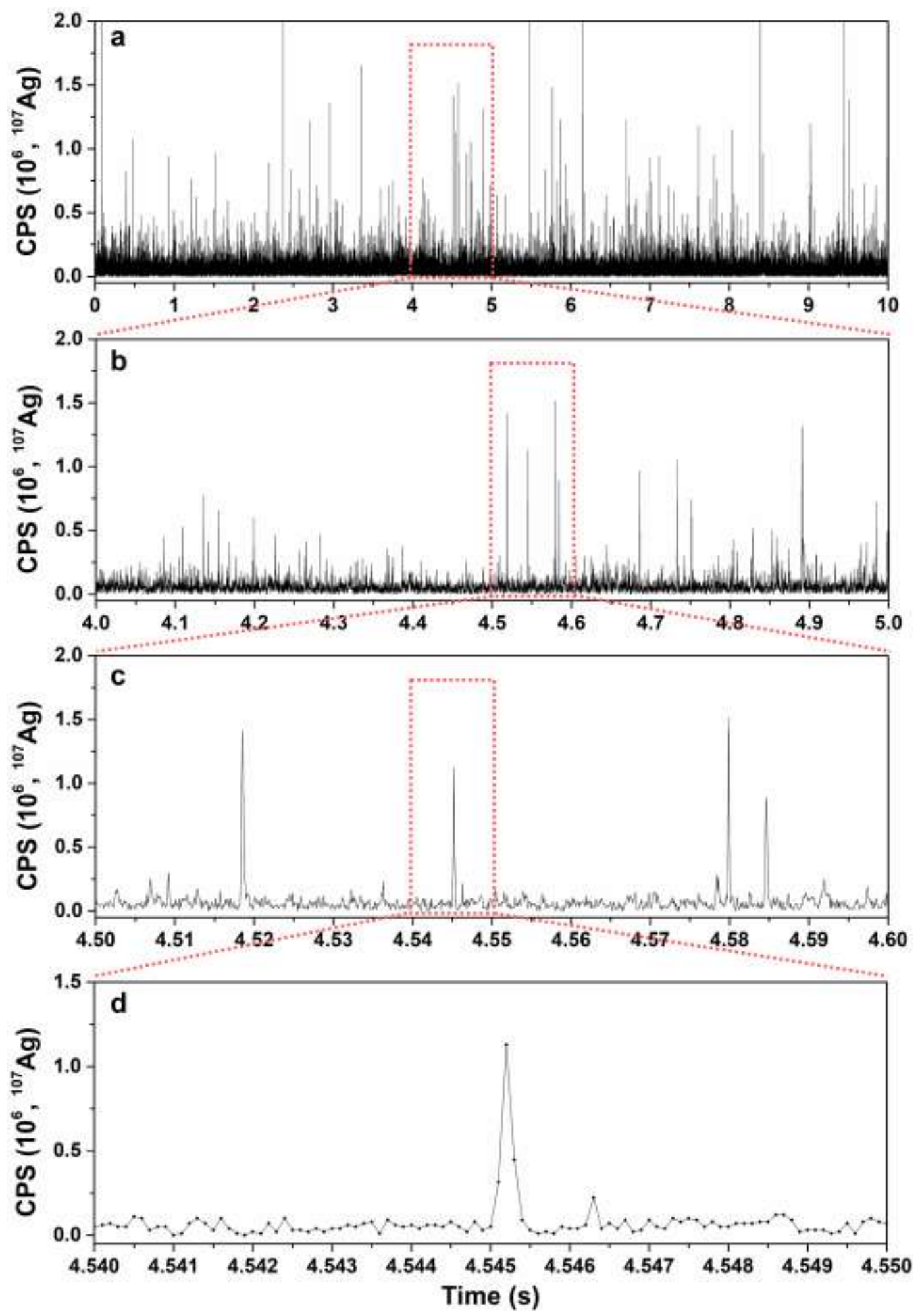

Figure S13. Single-cell CPS burst data during a $10 \mathrm{~s}$ (a), $1 \mathrm{~s}$ (b), $0.1 \mathrm{~s} \mathrm{(c),} \mathrm{and} 0.01 \mathrm{~s}$ (d) time windows achieved from ICP-MS of CytoLM. Experimental parameters: cell density, $1.5 \times 10^{5} / \mathrm{mL}$; velocity, $50 \mu \mathrm{L} / \mathrm{min}$. 
Table S1. ICP-MS Instrumental and Operational Parameters.

\begin{tabular}{ll}
\hline Operating parameter & Setting \\
\hline RF power (W) & 1550 \\
Plasma Ar gas flow (L/min) & 15 \\
Carrier Ar gas flow (L/min) & 1.0 \\
Sampling and intercepting cone & Nickel \\
Scanning mode & Time-resolved analysis \\
Dwell time (ms) & 0.1 \\
Isotope & $107 \mathrm{Ag}$ \\
\hline
\end{tabular}


Table S2. Results of Single-Fluorescence Particle Analysis by VCCS-LIF.

\begin{tabular}{|c|c|c|c|c|c|c|c|c|c|}
\hline $\begin{array}{l}\text { Parallel } \\
\text { sample }\end{array}$ & $\begin{array}{l}\text { Concentration } \\
(/ 100 \mu \mathrm{L})\end{array}$ & $>\delta_{s}$ & $<\delta_{e}$ & $<\delta_{m}$ & $\begin{array}{l}\text { Detected } \\
\text { signal }\end{array}$ & $\begin{array}{l}\text { Overlapping } \\
\text { peak }(\%)\end{array}$ & $\begin{array}{l}\text { Effective } \\
\text { signal }\end{array}$ & $\begin{array}{l}\text { Recovery } \\
(\%)\end{array}$ & $\begin{array}{l}\text { Throughput } \\
\text { (/s) }\end{array}$ \\
\hline 1 & 9160 & & & & 7633 & 4.07 & 7322 & 79.9 & 122.03 \\
\hline 2 & 9160 & $0.6 \cdot \sigma_{F 0}$ & $0 \cdot \sigma_{H O}$ & $20 \cdot \sigma_{H O}$ & 7507 & 4.49 & 7170 & 78.3 & 119.50 \\
\hline 3 & 9160 & & & & 7313 & 4.24 & 7003 & 76.4 & 116.72 \\
\hline
\end{tabular}

$\delta_{s}$ and $\delta_{e}$ : threshold value for the starting point and the end point identification;

$\delta_{m}$ : threshold value for the deduction of undesired peaks;

$\sigma_{H O}$ and $\sigma_{F O}$ : standard deviation of the baseline and the first derivative of the baseline. 